\title{
Aspectos antropológicos empresariales
}

\section{Anthropological aspects of business}

\author{
Marcos de Antonio García \\ Jubilado de las Escuelas Nacionales de Medicina del Trabajo. Universidad \\ Complutense y del Instituto Nacional de Medicina del Trabajo de Madrid.
}

Recibido: 22-06-10

Aceptado: 31-08-10

\section{Correspondencia:}

Marcos de Antonio García

Urb. Prado Largo, 63

28223 Pozuelo de Alarcón (Madrid). España

Tfno: 913520804

E-mail: marcosdeantonio@yahoo.es

En tiempos pretéritos las relaciones entre los empresarios y los empleados se manejaban en permanente contacto personal, y por tanto, tenían clara las expectativas de cada cual, pero con la llegada de la era industrial, la actuación en masa, el creciente maquinismo y la irrupción de nuevas tecnologías, alteró este equilibrio creando situaciones conflictivas desconocidas. Esta situación pudo aliviarse o remediarse gracias a la incorporación de la sociología y la psicología en los años veinte, de forma que dichas ciencias antropológicas, consideradas de especulación teórica, se afirmaron progresivamente en el mundo del trabajo, ofreciendo herramientas de excepcional valor para la resolución de los nuevos problemas, como son la adaptación del ser humano al trabajo, y de éste a la máquina, o al ambiente. Su especialización en cada tarea, así como de un modo inverso, la adecuación de la tarea al hombre, la conducta, las motivaciones, la fatiga, etc., y son estos temas precisamente en los que coinciden tanto los intereses de las personas con los de la empresa.

Efectivamente, todas las experiencias que se han hecho desde los célebres estudios de Hawhorne hasta nuestros días, han probado reiteradamente que una empresa bien equipada y poderosamente financiada puede quedar espectacularmente derrotada en la lucha competitiva, por otra mucho más modesta y sin apenas recursos materiales, si esta última sabe seleccionar, estimular, capacitar al personal y crear verdadero espíritu de equipo, logrando además la creación de un ambiente más satisfactorio, creativo y saludable para el trabajador.

Pero para el logro de este deseable fin, no son exclusivamente los estudiantes de ciencias sociales los que precisan dominar esta materia, sino toda persona relacionada con la problemática de la empresa tiene que conocer las enormes posibilidades de estas técnicas, que aportan generosas ventajas en tres aspectos principales: El personal, el productivo y el social.

El personal, porque el trabajo es una actividad donde el ser humano forja su vida, desarrolla su personalidad y a su vez influye en la vida y personalidad de los demás, a la vez el trabajo es una forma de hacerse a sí mismo y hacer a los demás, y en este sentido, un trabajo será tanto más eficaz en la medida en que ofrezca al trabajador la posibilidad de expresar su personalidad, desarrollándola y enriqueciéndola.

El trabajo es una actividad productiva, ya que cuando el ser humano trabaja produce algo que satisface o pretende satisfacer una necesidad, conveniencia o demanda de la sociedad y en este aspecto un trabajo será tanto más eficaz cuando más favorezca, mediante la expresión y el desarrollo de la personalidad del trabajador, una producción elevada.

Por último, el trabajo es una actividad social, ya que el hombre trabaja en una situación interpersonal y social, trabaja con otros y su trabajo también depende de otros, esto son las relaciones humanas existentes 
en toda empresa. El trabajo en este sentido es una forma de convivencia y una auténtica escuela de formación social, que bien orientada propicia la satisfacción laboral.

¿Por qué son estos temas importantes para el personal de los Servicios Médicos del Trabajo?. Pensemos que el mayor inconveniente para la eficacia del trabajo es que los tres aspectos o fines descritos -desarrollo de la personalidad, incorporación social y alta producción- se encuentran en conflicto casi permanente, a consecuencia de que toda situación laboral es de por sí inestable y cualquier cambio plantea una serie de conflictos, especialmente en nuestra época supercompetitiva y por ende en crisis cuasi permanente, en donde el que cubre los gastos de dichos servicios, por imperativo legal, no es la administración, sino la empresa, en un marco social de asistencia social extensa pero hasta ahora, eficiente.

Es preciso que el Servicio Medico ofrezca salud, pero también comprometiéndose con los principios y necesidades de la empresa, para no ser o parecer un apéndice costoso, inflacionista y potencialmente inútil a los ojos de los factores económicos empresariales, en la que no nos entendamos ni con el jefe de Recursos Humanos, como he visto en muchas ocasiones.

Y son de estos aspectos antropológicos de la empresa, tan poco tenidos en cuenta quizás por desconocidos por el personal médico, los que iremos desgranando en esta serie de trabajos que iniciamos. 